\title{
O Desenho Universal para Aprendizagem no acolhimento das expectativas de participantes de cursos de Educação a Distância
}

The Universal Design for Learning in the reception of the expectations of participants of Distance Education courses

El Diseño Universal para el Aprendizaje en la acogida de las expectativas de los participantes de cursos de Educación a Distancia

\author{
* Geisa Letícia Kempfer Bock \\ Professora doutora na Universidade do Estado de Santa Catarina (UDESC), Florianópolis, Santa Catarina, \\ Brasil. \\ geisabock@gmail.com - http://orcid.org/0000-0002-0272-2686

\section{** Marivete Gesser} \\ Professora doutora na Universidade Federal de Santa Catarina Campus Florianópolis, Florianópolis, Santa \\ Catarina, Brasil. \\ marivete@yahoo.com.br - http://orcid.org/0000-0002-4091-9754
}

\section{${ }^{* *}$ Adriano Henrique Nuernberg}

Professor doutor na Universidade Federal de Santa Catarina, Florianópolis, Santa Catarina, Brasil. adrianoh@outlook.com - http://orcid.org/0000-0002-7875-8490

Recebido em 28 de agosto de 2018

Aprovado em 09 de novembro de 2018

Publicado em 05 de junho de 2019

\section{RESUMO}

A eliminação das barreiras para garantir o acesso ao conhecimento de estudantes com distintos perfis de aprendizagem é um desafio nas diferentes etapas e modalidades de ensino. Na educação a distância, os planejamentos dos cursos e disciplinas devem contemplar as diferentes necessidades de todas as pessoas. Este estudo, de abordagem qualitativa, foi realizado com o intuito de verificar se os princípios e diretrizes do DUA (Desenho Universal para Aprendizagem) acolhem as expectativas de participantes de cursos de EaD no que se refere à participação com autonomia nessa modalidade de ensino. A coleta de dados ocorreu por meio da técnica Thinking aload, para isso contou-se com o software Ocam e, posteriormente, empregou-se a análise de conteúdos com apoio do software Atlas.ti 8.0 para tratamento dos resultados. Esse estudo antecede a oferta do curso de extensão para a comunidade e primou por contemplar a participação de pessoas com deficiência, inspirado pelos estudos emancipatórios. Acredita-se que a participação de pessoas com características diversificadas para aprendizagem é fundamental para a 
http://dx.doi.org/10.5902/1984686X34504

construção de ambientes mais inclusivos, desvelando necessidades de adequações em objetivos, materiais, estratégias, avaliações e organização do espaço virtual de aprendizagem. O framework do DUA contemplou as falas dos participantes revelando ser adequado para a aplicabilidade no planejamento e na oferta de cursos que se pretendem acessíveis, considerando, a priori, a existência de pessoas com diferentes características para participação e permanência nos cursos a distância.

Palavras-chave: Desenho universal para aprendizagem; Modelo social da deficiência; Educação a distância.

\section{ABSTRACT}

The elimination of the barriers to guarantee access to the knowledge of students with different learning profiles is a challenge in the different stages and modalities of teaching. In distance education, course and subject planning should address the different needs of all people. This qualitative study was carried out in order to verify if the principles and guidelines of the UDL (Universal Design for Learning) meet the expectations of participants in distance learning courses in relation to participation with autonomy in this type of teaching. The data collection was performed using the Thinking aloud technique. Ocam's software was used for this purpose, and content analysis with the support of the Atlas.ti 8.0 software was used to treat the results. This study precedes the offer of the extension course for the community and has been focused on the participation of people with disabilities, inspired by the emancipatory studies. It is believed that the participation of people with diversified learning characteristics is fundamental for the construction of more inclusive environments, revealing needs for adaptations in objectives, materials, strategies, evaluations and organization of the virtual learning space. The UDL framework contemplated the participants' statements, showing that it is appropriate for the applicability in the planning and offering of courses that are intended to be accessible, initially considering the existence of people with different characteristics for participation and permanence in distance courses.

Keywords: Universal design for learning; Disability social model; Distance education.

\section{RESUMEN}

La eliminación de las barreras para garantizar el acceso al conocimiento de estudiantes con distintos perfiles de aprendizaje es un reto en las distintas etapas y modalidades de la enseñanza. En la educación a distancia, las planificaciones de los cursos y disciplinas deben contemplar las distintas necesidades de todas las personas. Este estudio, con enfoque cualitativo, fue realizado con el fin de verificar si los principios y directrices del DUA (Diseño Universal para el Aprendizaje) acogen las exceptivas de los participantes de cursos de $E A D$ en lo que se refiere a la participación con autonomía en esa modalidad de enseñanza. La recopilación de datos se realizó por medio de la técnica Thinking aload, disponiendo para ello del software Ocam y, posteriormente, se utilizó el análisis de contenidos con el apoyo del software Atlas.ti 8.0 para la elaboración de los resultados. Este estudio antecede la oferta del curso de extensión para la comunidad y se distinguió por contemplar la participación de personas con deficiencia, inspirado por los estudios 
http://dx.doi.org/10.5902/1984686X34504

emancipadores. Se cree que la participación de personas con características diversificadas para el aprendizaje es fundamental para la construcción de ambientes más inclusivos, revelando necesidades de adecuación en los objetivos, materiales, estrategias, evaluaciones y organización del espacio virtual de aprendizaje. El framework del DUA tuvo en cuenta las deposiciones de los participantes mostrándose adecuado para la aplicabilidad en la planificación y en la oferta de cursos que pretendan ser accesibles, considerando, a priori, la existencia de personas con distintas características para la participación y permanencia en los cursos a distancia.

Palabras clave: Diseño universal para el aprendizaje; Modelo social de la discapacidad; Educación a distancia.

\section{Introdução}

A universalização de acesso ao ensino tem sido pauta de muitos debates e políticas públicas no Brasil, como exemplo desta expansão podemos citar o crescimento dos investimentos na Educação a Distância (EaD) e a criação da Universidade Aberta do Brasil (UAB) em 2005 (ANDRADE, 2013). Outro aspecto que pode ser observado são as adequações no ensino superior presencial que passa a ter, em algumas situações, uma proporcionalidade de sua carga horária a ser ofertada na modalidade de ensino a distância, o que demanda a ressignificação dos planejamentos de ensino e uso de recursos que possibilitem participação e autonomia por parte de todos os estudantes. O ensino superior na modalidade a distância chega a locais que até pouco tempo se pensava ser improvável a sua oferta, e com essa ampliação há também o acréscimo de matrículas de pessoas com deficiência. A flexibilização das distâncias e dos tempos de aprendizagem proporciona uma maior acolhida às distintas características de cada pessoa. No entanto, de acordo com Valente (2013), muito ainda precisa ser feito para que, além da transmissão de informações, o acesso ao conhecimento com equidade de condições seja uma realidade.

As ferramentas da Educação a Distância têm sido utilizadas para além do espaço do ensino superior formal, tal como ocorre em cursos de extensão ofertados para a comunidade, cursos de pós-graduação, apoio dos ambientes virtuais para cursos presenciais, entre outras situações em que a EaD se faz presente. É preciso demarcar que a expansão dessa modalidade não é garantia de inclusão. Tal como em ambientes presenciais, em ambientes virtuais podem residir barreiras que obstaculizam a participação de diferente sujeitos (BOCK et al., 2018), não apenas pela experiência da deficiência, mas por outras características como, por exemplo, a inabilidade com a tecnologia. 
http://dx.doi.org/10.5902/1984686X34504

A implementação de facilitadores e a eliminação de barreiras nos Ambientes Virtuais de Aprendizagem possibilitará maiores condições para participação, portanto, acredita-se que o planejamento, a organização e a disponibilização dos conteúdos e dos recursos utilizados nessa modalidade de ensino devem ser pensados numa ampla variabilidade para atender às especificidades dos possíveis partícipes. Para Rezende (2009), a incorporação do Desenho Universal na EaD é uma meta ética no enfrentamento da diferenciação pela deficiência vivenciada por muitos estudantes, tendo em vista que, ao modificar o ambiente, possibilitará maiores condições de participação para todos.

No entanto, apesar dessa expansão, pesquisadores como Barnes (2007), Gibson (2012), Gale e Tranter (2011), entre outros, indicam que as pessoas com deficiência ainda não estão representadas de maneira satisfatória no ensino superior, e as que conseguem acessar a este nível de ensino abandonam proporcionalmente em número maior do que as pessoas que não possuem deficiência. A permanência de pessoas com deficiência no espaço formal da educação precisa ser potencializada. Desta maneira, justifica-se a necessidade de estudos que contemplem distintos entendimentos para que se possa ter acessibilidade e participação no ensino a distância, a exemplo do entendimento sobre a eliminação de barreiras metodológicas, comunicacionais, atitudinais, entre outras. A supressão de tais barreiras permitirá que os estudantes com deficiência estejam de fato contemplados nas suas características de aprendizagem.

A partir do entendimento de que o modo como o estudante com deficiência aprende está inserido num espectro de possibilidades e variações humanas, Bock, Gesser e Nuernberg (2018) apontam que a experiência da deficiência em ambientes que não acolhem esta variação pode ser opressora. Nisso reside a necessidade de eliminação das barreiras metodológicas no ensino superior, o que corrobora com o rompimento do capacitismo. Em ambientes virtuais de aprendizagem essa grande variabilidade de perfis de aprendizes se faz presente, por isso, o campo de estudos sobre deficiência na educação busca estratégias e modalidades de ensino flexíveis e colaborativas que garantam não apenas a interação social como também a apropriação do conhecimento (VALLE; CONNOR, 2014). Tem-se o entendimento de que quando os currículos, as estratégias e as metodologias de ensino são projetados para atender às necessidades de uma "média", portanto, de um padrão normativo de funcionamento, provavelmente não contemplarão as variações corporais e as diferentes características de aprendizagem de uma grande parte dos estudantes, principalmente daqueles que possuem alguma experiência de deficiência. 
http://dx.doi.org/10.5902/1984686X34504

Os objetivos e as temáticas deste estudo surgem a partir dessas compreensões e dos seguintes pressupostos:

- A solução para a remoção das barreiras de acesso ao conhecimento deve ser construída com a participação dos estudantes com diferentes características para aprendizagem;

- Acessibilidade é algo relativo e não pode ser generalizado. Aquilo que facilita o acesso para alguns pode ser uma barreira para outros;

- A autonomia no acesso ao conhecimento tem relação direta com a oferta de recursos, metodologias e estratégias disponibilizados na EaD;

- A adoção de princípios e diretrizes do Desenho Universal para Aprendizagem - DUA -como exercício da ética do cuidado potencializa o rompimento com o capacitismo presente em cursos de EaD.

Em diferentes países o DUA tem sido implementado. Aliando pesquisas do campo da neurociência e da tecnologia tem inspirado a criação de situações e ambientes de aprendizagem mais acolhedores às variações dos estudantes. Pesquisas realizadas por Rao e Bryant (2014) e Rose e Meyer (2007) indicam que há possibilidades de qualificar os ambientes (físicos ou virtuais) para eliminar ou minimizar os enfrentamentos de barreiras que estudantes vivenciam em suas trajetórias escolares. Dessa maneira, estes podem ter acesso ao conhecimento com as condições de permanência e continuidade até os níveis mais elevados de ensino. O DUA tem se revelado como um grande aliado do modelo social da deficiência, ao compreender que a experiência da deficiência não se limita a um corpo com lesão, mas tem relação direta com os contextos que podem ser mais ou menos acolhedores das diferentes características das pessoas (BOCK et al., 2018).

Este estudo, de abordagem qualitativa, foi realizado com o intuito de verificar se os princípios e diretrizes do DUA acolhem as expectativas de participantes de um curso de EaD no que se refere à participação com autonomia nessa modalidade de ensino. Esse estudo ocorreu num ambiente virtual de aprendizagem no qual estava sendo planejado o Curso de Extensão em Estudos sobre Deficiência, primando por contemplar a participação de pessoas com deficiência, inspirado, assim, pelos estudos emancipatórios (MARTINS et al., 2012). Após essa participação de diferentes pessoas no planejamento, o curso será adequado para oferta à comunidade em geral. Acredita-se que a participação de pessoas com distintas características para aprendizagem é fundamental para a construção de ambientes mais inclusivos, desvelando necessidades de adequações nos objetivos, nos 
materiais, nas estratégias, nas avaliações e na organização do espaço virtual de aprendizagem.

\section{Da expectativa do usuário à incorporação dos princípios do DUA}

No reconhecimento de que pesquisas no campo da deficiência necessariamente devem assumir "um compromisso com a elisão das estruturas que marginalizam e silenciam as experiências das pessoas com deficiência" (Martins et al., 2012, p. 05) é que o presente estudo foi realizado. Com base nas informações obtidas junto aos participantes foi possível vislumbrar se os princípios e diretrizes do DUA eram viáveis e se, de fato, dariam conta de suprir as demandas indicadas pelos partícipes desse estudo.

Partiu-se do pressuposto de que é relevante considerar as três redes e os três princípios centrais do DUA na produção de cursos na modalidade a distância. Por meio deles, é possível a construção de relações de aprendizagem pautadas no cuidado e na interdependência em todas as etapas de implementação do ensino.

A primeira rede, a de reconhecimento, que tem por princípio os Meios de Representação, abarca as diferentes maneiras de acessar uma informação ou conteúdo, seja por meio de habilidades visuais, auditivas e outras (Rose et al., 2006). Com isso, tornase imprescindível observar a organização e a disponibilização de recursos no ambiente virtual de aprendizagem, de tal maneira que um conceito possa ser elaborado a partir de diferentes suportes de mídia (filme, texto, audiodescrições, LIBRAS, legendas, etc.) e como indicado nas expectativas, sem labirinto para acessar as informações.

A segunda rede, a estratégica, que tem como princípio a ação e a expressão, engloba a demonstração daquilo que o estudante aprendeu. Desse modo, o estudante expressará o conhecimento, na EaD, ao responder um questionário, participar de um fórum ou elaborar uma produção textual. Possibilidades para a participação precisam ser disponibilizadas, seja por escrita, filmagens, gravações, entre outros meios. Dessa maneira, o estudante tem autonomia na escolha dos recursos e das estratégias a fim de demonstrar o que aprendeu. Outro ponto a ser observado é a eliminação dos constructos irrelevantes na resolução de atividades e ampliação da relevância da avaliação (CAST, 2011).

A terceira rede é a afetiva, que corresponde ao princípio do engajamento, ou seja, o porquê da aprendizagem, a motivação que um estudante tem para aprender e a flexibilização e a disponibilização de vários meios que permite acolher as características de cada um, pois não existe uma norma para que a participação ocorra. De acordo com o 
CAST (2011), há uma variação grande de fatores que influenciam a rede afetiva, incluindo a cultura, a relevância pessoal, a subjetividade e os conhecimentos básicos. A falta de acessibilidade pode ser um dos gatilhos para a evasão nos cursos, pois quando os estudantes não conseguem acessar os materiais e conteúdos pode ocorrer uma diminuição do interesse pela permanência e participação.

Pensar acessibilidade na educação a distância é, de fato, algo bastante exploratório no cenário da educação brasileira, principalmente a partir do modelo social, no qual se compreende que a experiência da deficiência faz parte do ciclo de vida humano (Diniz, 2003). Com isso, os ambientes devem estar adequados para apoiar as pessoas nas suas características, reconhecendo os diversos marcadores sociais das diferenças - gênero, sexualidade, raça, classe social, deficiência, entre outros - como parte constituinte de todos os grupos. Muitos estudantes, em determinados momentos, podem vivenciar contextos excludentes tanto para participação quanto para acessar ao conhecimento. Com a finalidade de atingir um contexto acessível, as barreiras no currículo, nos métodos, nas estratégias, e nos recursos precisam ser eliminadas.

\title{
Metodologia
}

No intuito de construir uma metodologia de pesquisa que contemplasse as premissas do campo do Disability Studies in Education localizou-se as investigações emancipatórias da deficiência. Essa metodologia de pesquisa teve como precursores Michael Oliver, Colin Barnes, entre outros representantes da primeira geração do modelo social da deficiência. Nesse sentido, quatro princípios essenciais são elencados por Martins et al. (2012) como imprescindíveis para a adoção desta metodologia. São eles:

\begin{abstract}
a adoção do modelo social enquanto ferramenta teórica e enquanto perspectiva crítica privilegiada através da qual se apreende a realidade das pessoas com deficiência; o desenvolvimento de uma ciência politicamente empenhada e comprometida com as lutas das pessoas com deficiência; a responsabilização do investigador face aos sujeitos da investigação - as pessoas com deficiência e as suas organizações; e, finalmente, a utilização de metodologias de investigação suficientemente adaptáveis de modo a captar a complexidade do real e a valorizar a voz das pessoas com deficiência. (MARTINS, 2012, p. 05-06).
\end{abstract}

A partir desse entendimento e pautados nas premissas elencadas anteriormente, definiu-se o contexto, os partícipes e as técnicas para coleta e análise dos dados deste estudo que ocorreu no ano de 2017.

Contexto da pesquisa - A pesquisa foi realizada tendo por base o planejamento inicial do Curso de Extensão em Estudos sobre Deficiência, a ser ofertado pelo Núcleo de Estudos 
http://dx.doi.org/10.5902/1984686X34504

Sobre Deficiência - NED/UFSC. O planejamento, com base na perspectiva do DUA, visou eliminar barreiras contemplando os componentes inter-relacionados do currículo: objetivos, método, recursos e avaliação. No âmbito do DUA, este planejamento visa a potencialização da autonomia de estudantes em acessar e elaborar o seu conhecimento, ou seja, tudo é pensado vislumbrando uma maior flexibilização, a exemplo das metas e objetivos que não podem ser únicos mas precisam abarcar um espectro ampliado que contemple as diferentes expectativas dos estudantes, ou ainda, materiais que possam oferecer diferentes níveis de apoio e desafios, bem como avaliações que produzam feedbacks formativos e que ampliem o monitoramento da aprendizagem.

Após essa primeira etapa do planejamento, que ocorreu de maneira colaborativa com os professores responsáveis pelos conteúdos, bolsistas de graduação, designer instrucional e a pesquisadora de doutorado, deu-se o momento de implementação do curso com a participação do grupo inicial de pesquisa.

Visando avaliar as condições para a participação no curso de extensão, foi disponibilizado um roteiro orientando a exploração dos ambientes e recursos, deixando-se claro que os participantes não precisavam se limitar a ele. Neste roteiro, foram priorizadas ações que identificariam a presença de recursos e estratégias de acessibilidade. Todos foram convidados a transitar pelo ambiente virtual do curso, acessar recursos de vídeo, textuais e de áudio, assim como dar uma devolutiva num fórum de apresentação. $\mathrm{O}$ engajamento pode ser identificado quando as orientações conduziram a falas sobre a motivação para realizar cursos nessa modalidade e com essas temáticas, bem como nas situações em que os participantes localizaram alguma barreira ou situações de distração que necessitaram de enfrentamento para a realização da atividade orientada pelo roteiro.

Participantes - A composição do grupo piloto se deu por conveniência intencional, dez pessoas com distintas características para aprendizagem foram convidadas a participar dessa etapa da pesquisa, dentre elas estudantes do ensino superior e profissionais que atuam na área da deficiência, sendo que essas pessoas poderiam ter ou não experienciado a condição de deficiência. Uma carta convite foi entregue e, a partir do aceite, foi disponibilizado o Termo de Consentimento Livre e Esclarecido (TCLE). Após este ter sido lido e assinado iniciou-se o trabalho. Dentre os 10 convidados, 8 confirmaram a participação e somente 6 pessoas finalizaram todas etapas. 
Quadro 1 - Partícipes da pesquisa

http://dx.doi.org/10.5902/1984686X34504

\begin{tabular}{|l|l|l|l|}
\hline PARTíCIPE & CARACTERIZAÇÃO & \multicolumn{1}{|c|}{$\begin{array}{c}\text { OCUPAÇÃO } \\
\text { ATUAL }\end{array}$} & \multicolumn{1}{|c|}{$\begin{array}{c}\text { EXPERIËNCIA COM O } \\
\text { MOODLE }\end{array}$} \\
\hline - Sam & $\begin{array}{l}\text { Homem, sem } \\
\text { deficiência. }\end{array}$ & $\begin{array}{l}\text { Estudante de } \\
\text { graduação }\end{array}$ & $\begin{array}{l}\text { Participou de cursos que não } \\
\text { ofertaram a experiência com } \\
\text { recursos de acessibilidade. } \\
\text { Utilizou o Moodle na } \\
\text { graduação. }\end{array}$ \\
\hline 2-Teresa & $\begin{array}{l}\text { Mulher, sem } \\
\text { deficiência }\end{array}$ & $\begin{array}{l}\text { Profissional da } \\
\text { área da Educação } \\
\text { Especial }\end{array}$ & $\begin{array}{l}\text { Realizou cursos de EaD, tem } \\
\text { facilidade no uso da } \\
\text { tecnologia. }\end{array}$ \\
\hline 3- Mauro & $\begin{array}{l}\text { Homem com a } \\
\text { experiência da } \\
\text { deficiência, Síndrome } \\
\text { de Klinefelter }\end{array}$ & $\begin{array}{l}\text { Estudante do } \\
\text { ensino superior }\end{array}$ & $\begin{array}{l}\text { Parte de seu curso é a } \\
\text { distância, em outra } \\
\text { plataforma virtual. Conhece o } \\
\text { Moodle por conta de outras } \\
\text { atividades. }\end{array}$ \\
\hline $4-$ Duda & $\begin{array}{l}\text { Mulher com deficiência } \\
\text { visual }\end{array}$ & $\begin{array}{l}\text { Profissional da } \\
\text { área da } \\
\text { psicologia. }\end{array}$ & $\begin{array}{l}\text { Realizou diferentes cursos no } \\
\text { Moodle e atua num setor que } \\
\text { necessita desse recurso. }\end{array}$ \\
\hline 5- Kate & $\begin{array}{l}\text { Mulher com } \\
\text { experiência da } \\
\text { deficiência física }\end{array}$ & $\begin{array}{l}\text { Profissional da } \\
\text { área da educação }\end{array}$ & $\begin{array}{l}\text { Utilizou o Moodle na } \\
\text { graduação como apoio para } \\
\text { as disciplinas presenciais. }\end{array}$ \\
\hline 6-Giana & Mulher sem deficiência & $\begin{array}{l}\text { Profissional da } \\
\text { área da Educação } \\
\text { Especial }\end{array}$ & $\begin{array}{l}\text { Possui experiência com } \\
\text { diferentes plataformas, } \\
\text { inclusive o Moodle. }\end{array}$ \\
\hline OBS: Os nomes aqui utilizados são fictícios.
\end{tabular}

Fonte: Quadro elaborado pelos pesquisadores.

A técnica Thinking aload foi escolhida para a coleta de dados com o grupo piloto. Foi indicado o link para instalação do software Ocam para gravar em tempo real a fala do usuário e a tela do computador, captando o trânsito dos partícipes no ambiente virtual, potencializando, assim, a identificação de possíveis barreiras à participação para outras pessoas. Essa estratégia de verbalização em voz alta, originalmente utilizada em ensaios psicológicos, é crescente no campo da pesquisa e tem se mostrado muito promissora para compreender elementos da interação pessoa-computador. Villanueva (2004, p. 62) enfatiza que a técnica Think-aloud "consiste em observar usuários realizando tarefas e ações específicas, dentro de um ambiente específico. Estas ações são descritas pelos participantes em voz alta em tempo real". Para aqueles que não realizam intervenções orais, o registro poderia ser escrito ou com a captação da LIBRAS pela Webcam.

O procedimento de coleta de dados realizado pelos partícipes ocorreu prioritariamente de maneira individual, a distância, com suporte online da pesquisadora por Hangout, Skype e pelo próprio Moodle. Checklist com sugestões de ações foi encaminhada por e-mail para orientar tais procedimentos. No entanto, três participantes solicitaram a presença da pesquisadora no momento de realização do registro com o software Ocam. Não ocorreu 
http://dx.doi.org/10.5902/1984686X34504

nenhuma intervenção, a presença da pesquisadora foi requisitada somente pelo fato de os participantes se sentirem mais seguros para sanar dúvidas que poderiam surgir. Compreendendo a necessidade desse acolhimento devido às variações inerentes à condição humana, a pesquisadora se fez presente.

Os vídeos gravados foram compartilhados de diferentes maneiras, pelo Google Drive, YouTube, pen drives, respeitando a escolha dos participantes. Após o acesso do material gravado, iniciou-se a transcrição, categorização e análise. Adotou-se o método de análise de conteúdo categorial, apoiado pelo uso do software Atlas.Ti 8.0 para organizar as informações coletadas e categorizar as falas. Utilizou-se os trinta e um pontos de controle das nove diretrizes do DUA como categorias a priori (Quadro 2) e, posteriormente, essas categorias foram organizadas nos três grandes grupos de princípios do DUA anteriormente apresentados: Modos múltiplos de Apresentação, Modos Múltiplos de Ação e Expressão e Modos Múltiplos de Engajamento.

\section{Resultados}

Após a categorização dos dados coletados e a partir da observação da participação ativa dos sujeitos da pesquisa, registradas nos vídeos, percebeu-se que as diretrizes do DUA e suas subdivisões acolheram todas as falas inferidas, seja pela presença de recursos, estratégias ou metodologias que contemplassem suas expectativas, quanto pela ausência daquilo que Ihes possibilitasse maior participação e acesso ao conhecimento, ou ainda, pela indicação da existência de barreiras presentes nos recursos ou no próprio ambiente virtual. Cinco participantes tiveram suas falas transcritas e categorizadas e uma das participantes realizou toda a atividade sem acionar a gravação de voz, ficando inviável a análise dos dados e possibilitando uma reflexão sobre a necessidade de tutoriais ou outras maneiras que conduzam para ações assertivas. Dentre as falas dos partícipes, destacamse aquelas que tratam da categoria Modos Múltiplos de Apresentação, pois foram as que mais apareceram nos extratos da análise, posteriormente aparecem aquelas relativas à Ação e Expressão e, por fim, as que abordam o Engajamento.

Utilizou-se a Categorização Semântica, tendo sido definido, a priori, que as subdivisões de cada uma das diretrizes do DUA acolheriam as falas dos participantes, as quais, posteriormente, foram agrupadas pelas suas diretrizes e, finalmente, reagrupadas pelos princípios, tal como segue no quadro 2, a seguir: 
Quadro 2 - Diretrizes e Princípios do DUA

\begin{tabular}{|c|c|c|}
\hline Ponto de verificação & Diretrizes & Princípios e redes \\
\hline $\begin{array}{l}1.1 \text { - Personalização da apresentação da } \\
\text { Informação }\end{array}$ & \multirow{3}{*}{1 - Percepção } & \multirow{12}{*}{$\begin{array}{lr}\text { I } \quad \text { Modos } \\
\text { Múltiplos } \\
\text { Apresentação de } \\
\text { Rede de } \\
\text { Reconhecimento }\end{array}$} \\
\hline 1.2 - Alternativas à informação auditiva & & \\
\hline 1.3 - Alternativas à informação visual & & \\
\hline 2.1 - Esclarecer terminologias e símbolos & \multirow{5}{*}{$\begin{array}{ll}2 \quad-\quad \text { Uso da } \\
\text { linguagem, } & \\
\text { expressões } & \\
\text { matemáticas } & \text { e } \\
\text { símbolos } & \end{array}$} & \\
\hline 2.2 - Esclarecer sintaxe e estrutura & & \\
\hline $\begin{array}{l}2.3 \text { - Apoiar a decodificação de textos, } \\
\text { notações matemáticas e símbolos }\end{array}$ & & \\
\hline $\begin{array}{l}2.4 \text { - Promover a compreensão em } \\
\text { diversas línguas }\end{array}$ & & \\
\hline $\begin{array}{l}2.5 \text { - Ilustrar com exemplos usando } \\
\text { diferentes mídias }\end{array}$ & & \\
\hline $\begin{array}{l}3.1 \text { - Ativar ou providenciar conhecimentos } \\
\text { de base }\end{array}$ & \multirow{4}{*}{3 - Compreensão } & \\
\hline $\begin{array}{l}3.2-\text { Evidenciar iterações, pontos } \\
\text { essenciais, conexões e ideias principais }\end{array}$ & & \\
\hline 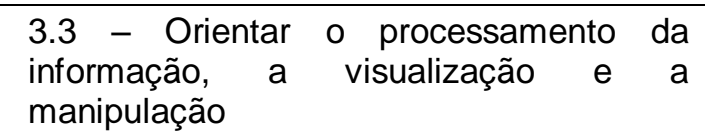 & & \\
\hline 3.4 - Maximizar o generalizar e o transferir & & \\
\hline $\begin{array}{l}4.1 \text { - Diversificar os métodos de resposta e } \\
\text { percurso }\end{array}$ & \multirow{2}{*}{4 - Atividade física } & \multirow{9}{*}{$\begin{array}{l}\text { II - Modos } \\
\text { Múltiplos de Ação } \\
\text { e Expressão - } \\
\text { Rede Estratégica }\end{array}$} \\
\hline $\begin{array}{l}4.2 \text { - Otimizar o acesso a tecnologias de } \\
\text { apoio }\end{array}$ & & \\
\hline $\begin{array}{l}5.1 \text { - Meios midiáticos múltiplos para a } \\
\text { comunicação }\end{array}$ & \multirow{3}{*}{$\begin{array}{l}5 \text { - Opções para } \\
\text { comunicação e e } \\
\text { expressão }\end{array}$} & \\
\hline $\begin{array}{l}5.2-\text { Instrumentos múltiplos para } \\
\text { construção e composição }\end{array}$ & & \\
\hline $\begin{array}{l}5.3 \text { - Construir fluências com níveis } \\
\text { graduais de apoio à prática e ao } \\
\text { desempenho }\end{array}$ & & \\
\hline $\begin{array}{l}6.1 \text { - Orientar o estabelecimento de metas } \\
\text { adequadas }\end{array}$ & \multirow{4}{*}{$\begin{array}{l}6-\text { Funções } \\
\text { executivas }\end{array}$} & \\
\hline $\begin{array}{l}6.2 \text { - Apoiar a planificação e estratégia de } \\
\text { desenvolvimento }\end{array}$ & & \\
\hline $\begin{array}{l}6.3 \text { - Interceder na gerência da informação } \\
\text { e dos recursos }\end{array}$ & & \\
\hline $\begin{array}{l}6.4-\text { Potencializar a capacidade de } \\
\text { monitorar o progresso }\end{array}$ & & \\
\hline $\begin{array}{l}7.1 \text { - Otimizar a escolha individual e a } \\
\text { autonomia }\end{array}$ & \multirow{3}{*}{7 - Interesse } & \multirow{4}{*}{$\begin{array}{lr}\text { III - } & \text { Modos } \\
\text { Múltiplos } & \text { de } \\
\text { Engajamento } & - \\
\text { Rede Afetiva }\end{array}$} \\
\hline $\begin{array}{l}7.2 \text { - Otimizar a relevância, o valor e a } \\
\text { autenticidade }\end{array}$ & & \\
\hline 7.3 - Minimizar a insegurança e ansiedade & & \\
\hline $\begin{array}{l}8.1 \text { - Elevar a relevância de metas e } \\
\text { objetivos }\end{array}$ & $\begin{array}{l}8-\text { Esforço e } \\
\text { persistência }\end{array}$ & \\
\hline
\end{tabular}


http://dx.doi.org/10.5902/1984686X34504

\begin{tabular}{|l|l|}
\hline $\begin{array}{l}8.2 \text { - Variar as exigências e recursos para } \\
\text { otimizar os desafios }\end{array}$ & \\
\hline $\begin{array}{l}8.3 \text { - Promover a colaboração e o sentido } \\
\text { de comunidade }\end{array}$ & \\
\hline 8.4 - Elevar o reforço ao saber adquirido & \\
\hline $\begin{array}{l}9.1 \text { - Promover expectativas e e } \\
\text { antecipações que otimizem a motivação }\end{array}$ & \\
\hline $\begin{array}{l}9.2 \text { - Facilitar a capacidade individual de } \\
\text { superar dificuldades }\end{array}$ & \multirow{2}{*}{9 - Autorregulação } \\
\cline { 1 - 1 } $\begin{array}{l}9.3 \text { - Desenvolver a autoavaliação e a } \\
\text { reflexão }\end{array}$ & \\
\hline
\end{tabular}

Fonte: Quadro organizado pela pesquisadora principal a partir das Diretrizes versão 2.0 do Desenho Universal para Aprendizagem (CAST, 2011).

Identificou-se nas falas dos cinco participantes a presença dos três princípios e das nove diretrizes do DUA. Alguns dos pontos de controle tiveram maior destaque, tais como: aqueles que tratam da percepção da informação (alternativas para informação visual e auditiva); os relativos à atividade física (diversificar os métodos de resposta e percurso, otimizar o acesso a tecnologias de apoio); os que abordam o interesse (a autonomia e a minimização das distrações); e, por fim, os que abarcam a linguagem (promover a compreensão em diversas línguas).

\section{Discussão}

As discussões dos resultados desse estudo serão organizadas de acordo com os três princípios do DUA. Tais discussões serviram como fios condutores da reavaliação do programa inicial do Curso de Extensão em Estudos sobre Deficiência, ofertado na modalidade a distância. A devolutiva de pessoas com perfis diferenciados e experiências distintas com a modalidade a distância alertou para diferentes aspectos da estruturação do curso e validou o uso do framework do DUA para ampliar as condições de equidade no acesso ao conhecimento em cursos de EaD. Esse framework pode servir como base para construir opções de recursos, estratégias, metodologias, entre outros quesitos, além de possibilitar a flexibilidade, que é necessária para maximizar as oportunidades de aprendizagem para todos os partícipes (CAST, 2011). Abaixo segue a discussão a respeito dos resultados com base nas categorias do estudo.

I- Modos Múltiplos de Apresentação - Esse princípio do DUA abarca indicações que possibilitam refletir sobre as diferentes maneiras pelas quais as pessoas captam as informações e o uso de distintos canais sensoriais, sendo que alguns se sentem mais confortáveis com recursos de voz e outros com imagens. Nesse estudo, ficou evidente a 
http://dx.doi.org/10.5902/1984686X34504

importância do modo como o conteúdo ou as informações são disponibilizados. Diferentes falas dos participantes apontam que recursos de imagem ou de voz foram relevantes para a apreensão da informação.

A incorporação do recurso de audiodescrição para equivalência textual de todas as imagens apresentadas no ambiente e os recursos de testagem foram percebidos por praticamente todos os partícipes e avaliada como importante. Kate apontou que "o recurso de retorno de voz é muito bom porque auxilia na compreensão do texto". Isso desvela que, para aqueles leitores com pouca fluência, esse recurso potencializa a participação, uma vez que equipara as condições, reduzindo os constructos irrelevantes para aprendizagem daquelas pessoas que sentem a leitura como uma barreira de acesso ao conhecimento. A ausência desse recurso foi identificada principalmente pela partícipe Duda. Em um dos vídeos testados aparecem imagens com uma música de fundo, nesse momento ela registra que "fica um silêncio e eu não sei o que está acontecendo". Essa situação de não acessar os conteúdos visuais para pessoas cegas tende a gerar desconforto e insegurança. Além disso, não ter acesso ao conhecimento que está sendo apresentado obstaculizará a compreensão dos conceitos.

Bock, Silva e Souza (2014) apontam que existe uma grande diferença entre descrever uma imagem ou audiodescrevê-la, sugerindo que qualquer pessoa pode realizar uma descrição. No entanto, a audiodescrição é um recurso de acessibilidade comunicacional, ou seja, com este recurso é possível romper algumas barreiras na elaboração de conceitos relacionados à informação visual. Sendo assim, faz-se necessário um conhecimento das técnicas e das normas necessárias, o que pode ser localizado na Nota Técnica n.21 (BRASIL, 2012), que trata das orientações para descrição de imagem na geração de material digital acessível (Projeto Mecdaisy). Este é um dos poucos documentos legais no Brasil, o que indica a necessidade de instituições de ensino superior possuírem, em seu corpo de profissionais, equipes especializadas para apoiar a produção da audiodescrição.

O uso de legendas nos vídeos foi percebido e avaliado de modo distinto. O partícipe Mauro diz que a legenda "ajuda na atenção", destacando que ao focar na legenda ele não se distrai com outras situações e, quando é necessário, consegue acessar as imagens dos vídeos. Entretanto, a partícipe Duda não significa a legenda como um recurso necessário à sua condição de participação, pois os recursos precisam ser disponibilizados de maneira a serem acessados pela audição preferencialmente. Existem diferentes estudos sobre acessibilidade audiovisual, o que chama atenção é a especificidade do uso de legendas 
http://dx.doi.org/10.5902/1984686X34504

para surdos ou pessoas ensurdecidas que segue um padrão diferenciado daquele destinado para pessoas ouvintes. Araújo (2011) aponta três diferenças principais: 1) introdução de informações adicionais dependentes do canal auditivo para que aqueles com deficiência possam acompanhar filmes e programas de televisão; 2) questões técnicas; e 3) concepção de tradução. Dentre as informações adicionais encontram-se as marcações dos falantes, que no Brasil ocorre com o nome entre colchetes e os efeitos sonoros demarcados.

Sobre o recurso textual, Mauro aponta a necessidade de que textos longos tenham imagens para descanso da visão. Para as características desse sujeito, as disponibilizações dos recursos textuais devem ser curtas, ordenadas e com imagens que ampliem 0 entendimento da informação, efetivando-se como uma pausa para a sequência da leitura, tempo necessário para organizar o pensamento. A participante Duda indica que siglas utilizadas ou abreviações, assim como hyperlinks ao longo dos textos, são bastante inconvenientes para usuários de leitores de tela. Outra situação se refere a termos em inglês que o leitor lê sem a pronúncia correta, o que indica a necessidade de disponibilizar os textos com maior cuidado a essas situações.

A utilização de títulos nas seções é algo bem avaliado pelos partícipes, tanto pelo fato de organizar os recursos de maneira visual como pela lógica da navegabilidade no espaço da plataforma com a tecla $\mathrm{H}$ com o software leitor de tela Jaws. No Brasil, três sistemas são os mais utilizados pelo público que experiencia a deficiência visual, sendo eles o Dosvox, o Jaws e o Virtual Vision. Dentre os três, o Jaws foi utilizado pela partícipe Duda, a qual aponta como uma grande vantagem a possibilidade de este sistema permitir a utilização de teclas de atalho. As pesquisadoras Sonza e Santarosa (2003) destacam que usuários do Jaws podem trabalhar tão rapidamente quanto qualquer outro usuário de computador se este sujeito souber utilizar as teclas de atalho, o que corrobora com a lógica de organização do espaço virtual para um melhor aproveitamento dos recursos desse software.

Outro ponto que fica evidenciado pelos participantes é a disponibilização das orientações para realização das atividades. Kate diz que, quando o professor apenas deixa o material disponível na plataforma, o estudante fica inseguro sem saber o que é para fazer. Assim, deixar evidenciadas as metas de aprendizagem no uso de cada material é entendido como um facilitador. Sam sugere que quando há um recurso textual (tal como um programa orientador/planejamento) para acompanhar a sequência das atividades do curso, faz-se necessário que a disponibilização do material no ambiente virtual siga a mesma sequência 
http://dx.doi.org/10.5902/1984686X34504

do material textual, ou seja, que se mantenha a mesma ordem e organização para facilitar o trânsito e o direcionamento pelo espaço virtual.

Ainda sobre a disponibilização dos recursos no espaço virtual, Teresa indica que é interessante que os tópicos do curso, com seus recursos de aprendizagem, apareçam de maneira paulatina, não todos de imediato no primeiro acesso pois é muita informação. Todos os participantes avaliaram como positivo ter uma tela inicial apresentando a completude das temáticas e metas de aprendizagem do curso, essa estrutura, semelhante a um sumário comentado, possibilita uma ideia do todo.

Um dos pontos de verificação que teve destaque nas falas foi o de promover o conhecimento interlinguístico, ou seja, a compreensão em diversas línguas, isso porque, quando se pensa em organizar um curso em EaD, surgem diferentes aplicativos ou softwares gratuitos que poderiam ser disponibilizados para uso concomitante. Entretanto, em grande parte, esses recursos estão em outra língua e, para alguns sujeitos, esse facilitador pode se tornar uma barreira. Isso foi identificado por diferentes falas ao longo da testagem, a exemplo no uso do software Ocam, utilizado nessa pesquisa que trouxe as orientações para uso e instalação em Inglês, o que gerou insegurança para alguns partícipes. Ainda se testou o Book Builder (livro digital acessível) com audiodescrição gratuita. No entanto, a voz baseava-se na fonética do português de Portugal, o que gerou uma certa inquietação. A participante Teresa diz "Legal, só que ela está falando em português de Portugal e eu não sei como mudar"; ela ficava um tempo tentando trocar a voz, o que não é possível. Esse tipo de reação pode gerar um afastamento do objetivo principal no uso desse recurso. A inquietude com uso de língua estrangeira repete-se com os partícipes Duda e Mauro. Em outro momento, foi indicado uma parte de um texto no slide que está escrita em inglês e Teresa sugere não ser interessante manter a terminologia original nessa língua e sim substituí-la pela escrita em português. Outra situação com a língua estrangeira é sinalizada pela partícipe Duda, quando diz "ai, tem umas coisas em inglês aqui, não estou conseguindo entender porque o sintetizador de voz fala exatamente como está escrito, então é muito ruim”. Essas e outras falas evidenciam o quanto a língua estrangeira surge como uma barreira para a participação e para a autonomia, situação que chama a atenção para pensar a acessibilidade.

Esse é o primeiro princípio e revela uma enormidade de situações que carecem de uma atenção para que a disponibilização dos conteúdos e recursos estejam de acordo com a variação nos modos de acessar as informações. Sabe-se que não existe um único meio 
que contemplará todas as pessoas. Assim, exercitar o cuidado no plano público também tem relação direta com essas escolhas para o planejamento, uma vez que, no momento de ofertar um curso na modalidade a distância, deve-se construir ambientes de aprendizagem que contemplem da melhor forma possível a variação humana desde o planejamento inicial, considerando, a priori, a existência das diferenças no processo de captação das informações e oferecendo ajustes posteriores caso esses ainda sejam necessários.

II - Modos Múltiplos de Ação e Expressão - Esse é o segundo princípio do DUA e está diretamente relacionado com a rede estratégica, ou seja, como cada pessoa expressa o que sabe, quais os modos principais para conseguir demonstrar com organização, estratégia e prática aquilo que desejam. Algumas pessoas possuem melhor habilidade com a fala, outras com escrita e ainda há as que se expressam com desenhos, esquemas, etc. Oportunizar modos diferenciados de as pessoas darem suas devolutivas é respeitar essa variação de ser e estar no mundo.

O destaque nessa categoria foi o Ponto de Verificação Usar mídias diferenciadas. Na avaliação da maioria dos partícipes, a possibilidade de participação com gravação de áudio, imagens para além da escrita, é uma maneira de eliminar parte das barreiras na EaD. Muitas vezes são colocados constructos irrelevantes para a participação das pessoas, a exemplo de quando as atividades preveem uma única e exclusiva maneira de demonstrar o conhecimento, tal como ocorre ao exigir que se escreva sobre determinado assunto. Escrever, para algumas pessoas, pode ser uma barreira para a participação com autonomia. Mauro sugere que essa variabilidade de possibilidades na ação auxilia também no esclarecimento de dúvidas que possam surgir ao longo do curso, com base em sua experiência de graduação utilizando ambiente virtual de aprendizagem, indica que "facilita bastante poder incluir textos e fotos porque às vezes você pode falar mil coisas, mas a imagem mostra tudo que você sente, que você fala, que você quer dizer e não conseguiu falar" e diz ainda "imagem e vídeo, para mim é muito bom, ainda mais quando você quer tirar dúvidas com amigos e professores e não consegue falar, aí você pode mostrar uma imagem e tirar dúvida com eles".

De acordo com a análise de dados obtidos evidenciou-se que, para alguns partícipes da pesquisa, o uso de estratégias diferenciadas para a participação é relevante, entretanto, para outros tornou-se imprescindível, como é o caso de Kate, que experiencia uma mobilidade reduzida dos membros superiores. Segundo ela, "poder realizar atividades com gravação de vídeo e áudio facilita muito, porque a digitação é cansativa". $\mathrm{Na} \mathrm{EaD,} \mathrm{as}$ 
http://dx.doi.org/10.5902/1984686X34504

relações são pensadas a priori na oferta de espaços e recursos, e ter ciência de que "não é a vulnerabilidade ou a dependência que impedem o desenvolvimento de um agente autônomo, mas certos tipos de relacionamento (opressivos, exploradores, desrespeitosos, paternalistas etc.)" (Zirbel, 2016, p. 172). A adoção de recursos específicos é imprescindível para que as equipes pedagógicas modifiquem, nos planejamentos e nas ofertas de cursos, os modos de contemplar a participação, estabelecendo relações que favoreçam o exercício da autonomia.

Para além disso, se a comunicação é ampliada por outros canais de comunicação, a exemplo de um e-mail de suporte externo ao ambiente virtual, em situações de problemas de acesso, ainda existirá uma possibilidade de estabelecer uma comunicação. Isso também é a lógica da interdependência na potencialização da autonomia, pois quanto mais recursos disponíveis o cursista tiver, mesmo que algum deles falhe, ainda assim ele permanecerá assistido nas suas necessidades. Isso ocorre com a partícipe Teresa que, ao tentar acessar a primeira vez a plataforma do Moodle, teve problemas com seus login e senha; registrou na sua gravação que faria contato por e-mail, como, de fato, o fez e o problema foi resolvido.

Outro destaque nessa categoria é o ponto de verificação Diversificar o método de resposta e o percurso. Essa navegabilidade no ambiente virtual tem relação com a experiência com a tecnologia, mas também com os facilitadores desse espaço virtual. Fica evidente nas falas da partícipe Duda o quanto o domínio da tecnologia foi relevante para driblar problemas da estrutura do ambiente virtual. Como usuária do Jaws, diferentes teclas de atalho auxiliam no trânsito pelos diferentes espaços e recursos do Moodle. Isso fica evidenciado em algumas de suas falas, tais como: "primeiro vou começar com a tecla TAB, ir para conteúdo principal”, "eu suponho que aqui seja com Ctrl e seta para esquerda, estou procurando outra maneira, porque se eu não soubesse esse atalho eu não saberia sair". Isso revela o quanto o ambiente pode ser um complicador se estiver com labirintos no percurso. Não basta apenas um bom planejamento de ensino pautado no DUA, o espaço que acolhe o curso não pode ser um complicador para o desenvolvimento de práticas mais inclusivas. Esse espaço deve possibilitar aos docentes implementarem estratégias variadas.

Diferente da experiência vivenciada por Duda com o uso do leitor de tela Jaws, Mauro, que é vidente, diz que ter acesso visual na parte superior da página para ir direto para o próximo tópico "facilita muito para quem quer encurtar a história". Ele complementa "tem isso daqui que também ajuda, pois você pode clicar no próprio link que já vai para a página 
http://dx.doi.org/10.5902/1984686X34504

do conteúdo". As possibilidades diferenciadas de navegabilidade devem estar presentes no intuito de permitir as escolhas de cada pessoa e que estas escolhas estejam condizentes com as suas características de funcionalidade. Essa disponibilização é essencial para favorecer a chamada autonomia relacional na EaD, que deve estar atenta e ciente em "como as relações sociais impedem ou implementam as capacidades necessárias à autonomia" (Zirbel, 2016, p. 172). Podemos dizer que existe um mito do sujeito plenamente autônomo, todavia, a autonomia aqui defendida é uma experiência de interdependência. No espaço virtual, quanto maiores forem as ofertas de recursos maiores serão as possibilidades de vivenciar a autonomia.

Para além disso, evidenciou-se ser de extrema relevância para a vivência dessa autonomia o ponto de verificação Otimizar o acesso a tecnologias de apoio, pois tanto os espaços virtuais quanto os recursos de aprendizagem devem ser planejados e disponibilizados de modo que os estudantes possam utilizá-los de acordo com as suas caraterísticas, a exemplo dos leitores de tela, teclados virtuais, ampliação de letras, entre outras situações. Proporcionar justiça e equidade de condições para participação na EaD ainda é uma temática que deve ser melhor explorada, mas acredita-se ser relevante incorporar os princípios e diretrizes do DUA enquanto horizonte para implementação dos princípios da ética do cuidado nessa modalidade de ensino.

III - Modos Múltiplos de Engajamento - esse princípio diz respeito a tudo aquilo que envolve e mantém o estudante motivado e interessado em aprender. Os motivos são os mais variados, no entanto, existem situações que se colocam como barreiras e podem desmotivar e levar à desistência.

Dentre as indicações localizadas nas falas dos partícipes, um dos destaques é para a diretriz Interesse, pois foi verificada a presença de todos os seus pontos de verificação nas inferências dos cinco sujeitos da pesquisa. Ocorreu uma ênfase no ponto Minimizar a insegurança e ansiedade. Teresa sugere que o espaço do mural no ambiente virtual seja utilizado para que se mantenham atualizados os calendários e as orientações de eventos. Isso ameniza a possibilidade de esquecimento do cumprimento de prazos. Mauro, considerando suas características de aprendizagem, destaca que as orientações devem ser breves, objetivas e estejam, preferencialmente, em arquivos separados para não se apresentarem como barreiras e sim como facilitadores. Indica, ainda, que o uso de retorno de voz concomitante à leitura é interessante pois "quando uma pessoa está sonolenta, ou mais tarde da noite, ela pode colocar a gravação para ouvir". O excesso de material ou uma 
http://dx.doi.org/10.5902/1984686X34504

quantidade de páginas demasiada em recursos de textos foi apontado como um fator de ansiedade. Sugeriu-se que arquivos muito densos sejam separados e apresentados numa divisão por capítulos.

Uma das falas de Mauro indica a relevância de se selecionar vídeos do YouTube que não possuam propagandas, pois a presença delas foi considerada um motivo de distração. $\mathrm{Na}$ organização do Moodle, Duda sugere que ao clicar em links de textos ou vídeos no ambiente virtual, estes materiais sejam abertos em uma nova janela, para que, ao finalizar a atividade e fechar a janela, não ocorra o equívoco de fechar a página do curso no Moodle. Isso também é observado nas falas de Sam e Kate, esta diz o seguinte: "prefiro abrir muitas páginas do que fechar a página do curso".

Outro ponto de verificação que se revelou muito presente nas falas foi Promover expectativas e antecipações que otimizem a motivação. Uma das questões relevantes foi a tela de abertura com a visão geral das expectativas por tópico do curso. Sam destaca que "num primeiro acesso está bem visível qual a intenção do curso e o que é que vai ter em cada tópico". Sobre o ponto referente a expectativas e antecipações que otimizem a motivação, é indicado pelos pesquisadores do CAST que sejam promovidas atividades para incentivar a autorreflexão, ou seja, modular as reações e estados emocionais a fim de ser mais eficaz no enfrentamento e no engajamento nos contextos (CAST, 2011). Trata-se do reconhecimento das metas pessoais como modo de proporcionar a autorregulação, uma das diretrizes do princípio III.

Esse terceiro princípio do DUA, o Engajamento, tem relação direta com a afetividade, a motivação e o envolvimento com a aprendizagem, portanto, é um aspecto a ser considerado ao se pensar uma EaD comprometida com a variação no modo de participação. Mas, além disso, trata-se de um princípio que atenta para diferentes elementos culturais, relevância pessoal, entre outros fatores que se desvelaram significativos para possibilitar a permanência, algo além do direito de acesso ao ensino. A atenção ao princípio do Engajamento é uma ação que deve ser contínua e com uma escuta atenta às falas dos participantes, pois possibilitará coadunar com as teóricas da segunda geração do modelo social da deficiência ao assumir que, "embora a partir da posição que todos têm os mesmos direitos humanos, também reconhece os requisitos adicionais que algumas pessoas têm, a fim de ascender a esses direitos humanos”. (MORRIS, 2001, p.15). A necessidade por recursos adicionais surge no cotidiano, portanto, faz-se necessária a 
elaboração de currículos, estratégias, recursos flexíveis, customizáveis e uma docência emancipatória e acolhedora dessas necessidades.

\section{Considerações finais}

A busca por maior participação e acesso ao conhecimento pelos distintos sujeitos da educação não é uma preocupação exclusiva do campo de estudos sobre deficiência, nem, tampouco, algo a ser investigado numa única etapa, nível ou modalidade de ensino. Estudos para consolidar práticas inclusivas, pautadas no modelo social da deficiência, ainda são escassos e, portanto, com diferentes necessidades e caminhos para investigação. Nesse estudo efetivou-se um recorte para a modalidade de ensino a distância no nível superior. Embora tenha sido dado enfoque num curso de extensão, os partícipes selecionados foram ou são estudantes desse nível de ensino. Essa investigação atentouse para as falas dos participantes de modo a compreender se os princípios e diretrizes do DUA atendiam às suas expectativas no que se refere à oferta dos recursos e estratégias metodológicas que contemplem diferentes perfis de aprendizagem. O framework do DUA contemplou as falas dos participantes, revelando ser adequado para a aplicabilidade no planejamento e na oferta de cursos que se pretendem acessíveis, considerando, a priori, a existência de pessoas com diferentes características para participação e permanência nos cursos a distância. Levou-se em conta também, e principalmente, os modos e os meios pelos quais os sujeitos podem receber ou realizar devolutivas da sua aprendizagem, para além das características da deficiência/lesão.

As informações obtidas foram muito esclarecedoras e potencializaram mudanças nos recursos ou nas estratégias a serem incorporadas em cursos de EaD, pois desvelaram barreiras e facilitadores. Contudo, o terceiro princípio do DUA, o Engajamento, por sua complexidade, precisa ser melhor investigado em situação de participação num contexto real, com resolução das atividades durante a vigência de um curso nessa modalidade de ensino.

Os princípios e diretrizes do DUA se revelaram promissores para a orientação de ações que corroborem com a adoção da ética do cuidado na EaD. Suas perspectivas são relacionais, pois permitem localizar demandas nos currículos desde os planejamentos até os contextos das práticas, além de atentar-se às necessidades individuais dos sujeitos. $O$ DUA, enquanto fio condutor de práticas pedagógicas, mostrou-se potente para 0 enfrentamento do capacitismo. Sugere-se que pesquisas com outras abordagens e 
http://dx.doi.org/10.5902/1984686X34504

técnicas de coleta de dados sejam realizadas para complementar os dados desse estudo, tais como pesquisas sobre efetividade, comparativas e longitudinais.

Vislumbrar práticas que redimensionem e desloquem o olhar pedagógico da lesão no corpo para as relações estabelecidas entre sujeitos da aprendizagem e profissionais, estratégias e recursos é significativo para que o propósito do DUA seja alcançado. Zerbato (2018) chama atenção para a aproximação desse propósito com os princípios de uma educação inclusiva,

pois entende-se que é importante, em parceria com professores especializados e outros profissionais, a elaboração de recursos, materiais, atividades e espaços educativos e flexíveis para o aprendizado de todos os alunos, contemplando, assim, a diversidade, os diferentes estilos e ritmos de aprendizagem (Zerbato \& Mendes, 2018, p.152).

Dessa maneira, a acessibilidade será pensada para todos sujeitos e não para um público específico. Essa é a diferença entre uma educação inclusiva interseccional daquela que é pensada exclusivamente a partir da existência de um grupo minoritário.

\section{Referências}

ANDRADE, Luciane Sá de. O acesso à educação e os polos de apoio presencial: Sujeitos em Transformação. In: Mill, Daniel; Pimentel, Nara (Orgs.). Educação a Distância: desafios contemporâneos. São Carlos: EdUFSCar, 2013. p. 185-198.

ARAÚJO, Vera Lúcia Santiago; NASCIMENTO, Ana Katarinna Pessoa do. Investigando parâmetros de legendas para surdos e Ensurdecidos no Brasil. Tradução em Revista, Rio de Janeiro, n. 2, p. 1-18, nov. 2011.

BARNES, Colin. Deficiência, o ensino superior e a sociedade inclusiva. British Journal of Sociology of Education, n. 28, p. 135-145, dez. 2007.

BOCK, Geisa Letícia Kempfer; SILVA, Solange Cristina da; Souza, Carla Peres. A audiodescrição como recurso de acessibilidade ao conhecimento no ensino superior a distância. In: XI CONGRESSO BRASILEIRO DE ENSINO SUPERIOR A DISTÂNCIA, 2014, Florianópolis. Anais do XI Congresso Brasileiro de Ensino Superior a Distância. Florianópolis: NUTE-UFSC, 2014. Disponível em: <http://esud2014.nute.ufsc.br/anaisesud2014/>. Acesso em: 20 jan. 2018.

BOCK, Geisa LETÍCIA Kempfer; GESSER, Marivete; NUERNBERG, Adriano Henrique. Desenho Universal para a Aprendizagem: a Produção Científica no Período de 2011 a 2016. Revista Brasileira de Educação Especial, n. 1, v. 24, p. 143-160, jan./mar. 2018.

BRASIL. Norma técnica $\cong$ 21/2012, de 10 de abril de 2012. Orientações para descrição de imagem na geração de material digital acessível - Mecdaisy. Brasília: MEC/SECADI/DPEE, 2012. 
CAST. Desenho Universal para Orientações de Aprendizagem versão 2.0. Wakefield, MA: Autor, 2011.

DINIZ, Debora. Modelo social da deficiência: a crítica feminista. SérieAnis, Brasília, v. 28, p. 1-10, jul. 2003.

GALE, Trevor; TRANTER, Deborah. A justiça social na educação superior australiana política: uma conta histórica e conceitual da participação dos alunos. Estudos Críticos em Educação, n. 1, v. 52, p. 29-46, mar. 2011.

GIBSON, Suanne. Narrative accounts of university education: socio-cultural perspectives of students with disabilities. Disability \& Society, n. 27, v. 3, p. 353-369, abr. 2012

MARTINS, Bruno Sena; FONTES, Fernando; HESPANHA, Pedro; Berg, Aleksandra. A emancipação dos estudos da deficiência. Revista Crítica de Ciências Sociais, n. 98, p. 45-64, jun. 2012.

MORRIS, Jenny. Impairment and Disability: Constructing an Ethics of Care That Promotes Human Rights. Hypatia, n. 4, v. 16, p. 1-16, nov. 2001.

RAO, Kavita; OK, Min Wook; BRYANT, Brian R. A Review of Research on Universal Design Educational Models. Remedial and Special Education, n. 35, v. 3, p. 153-166, fev. 2014.

REZENDE, Flávia Aamaral. Educação Especial e a EAD. In: Litto, Frederic Michael; Formiga, Marcos (Orgs.). Educação a Distância: o estado da arte. São Paulo: Pearson Education do Brasil, 2009. p. 129-140.

Rose, David; MEYER, Anne. Teaching every student in the digital age: Universal Design for Learning. Retrieved. Alexandria: Association for Supervision and Curriculum Development. 2007.

ROSE, David et al. Universal design for learning in postsecondary education: Reflectionson principles as their application. Journal of postsecondary Education and Disability, n. 19 (2), maio 2006.

SONZA, André Poletto; SANTAROSA, Lucia Maria Costi. Ambientes digitais virtuais: acessibilidade aos deficientes visuais. RENOTE: revista novas tecnologias na educação, Porto Alegre, n. 1, fev. 2003.

VALENTE, José Armando. O Papel da Interação e as diferentes abordagens pedagógicas de Educação a Distância. In: Mill, Daniel; Pimentel, Nara (Orgs). Educação a Distância: desafios contemporâneos. São Carlos: EdUFSCar, 2013. p 25-42.

VALLE, Jan; CONNOR, David. Ressignificando a deficiência: da abordagem social às práticas inclusivas na escola. Porto Alegre: AMGH, 2014.

VILLANUEVA, Rochelle de Asa. Think-aloud protocol aril heuristic evaluation of nonimmersive, desktop photo-realistic virtual environments. Nova Zelandia: University of Otago, 2004. 
ZERBATO, Ana Paula; MENDES, Enicéia Gonçalves. Desenho universal para a aprendizagem como estratégia de inclusão escolar. Educação Unisinos, n. 22, v. 2, p. 147-155, abr./jun. 2018.

ZIRBEL, Ilze. Uma teoria político-feminista do cuidado. Florianópolis: Universidade Federal de Santa Catarina, 2016.

\section{Correspondência}

Geisa Letícia Kempfer Bock - Universidade do Estado de Santa Catarina (UDESC). Av. Me. Benvenuta, 2007 - Itacorubi, Florianópolis. CEP: 88035-901. Florianópolis, Santa Catarina, Brasil.

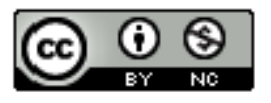

This work is licensed under a Creative Commons Attribution-NonCommercial 4.0 International (CC BY-NC 4.0) 